\title{
Exploration on Folk Songs of Yi Nationality in Liangshan from Perspective of Intangible Cultural Heritages
}

\author{
Dan Wang \\ College of Music, China West Normal University, Nanchong Sichuan, 637009, China
}

Keywords: Intangible cultural heritage, Folk songs of the Yi nationality in Liangshan, Social function, artistic value.

\begin{abstract}
Folk songs of the Yi nationality in Liangshan are one of intangible cultural heritages of China. Yi Autonomous Prefecture of Liangshan is the largest agglomeration area of the Yi nationality in China, which is called as the hometown of song and dance. Folk songs of the Yi nationality in Liangshan are rich in species and simple with unique national features. As one of the treasures in Chinese national music culture, they have many social functions and great artistic value. This paper explores the artistic value and social functions of folk songs of the Yi nationality in Liangshan from the perspective of intangible cultural heritage protection so as to improve the importance attached to folk songs of the Yi nationality in Liangshan and inherit excellent intangible cultural heritages in China.
\end{abstract}

\section{Introduction}

Relevant regulations on intangible cultural heritage have clearly pointed out the importance of excellent traditional folk culture in China and taken necessary measures for protecting such traditional culture. China always adheres to the principle of protection first for intangible cultural heritage. Folk songs of the Yi nationality are an important constituent part of Yi culture. The protection of folk songs of the Yi nationality is an effective protective measure for folk culture of the Yi nationality. Folk songs of the Yi nationality in Liangshan have wide contents of lyrics which contain folk culture and regional features of the Yi nationality in Liangshan. The melody and means of expression of such songs have unique artistic characteristics. Folk songs of the Yi nationality in Liangshan have made great contributions to the development and innovation of Chinese national vocal music culture and art. Their artistic value and social functions make it necessary to inherit and protect them well.

\section{Artistic value of folk songs of Yi nationality in Liangshan}

\subsection{Promote overall development of music culture of Yi nationality in Liangshan}

Folk songs of the Yi nationality in Liangshan have recorded all aspects in the production and life of laboring people of the Yi nationality. Old singers of the Yi nationality in Liangshan often impart knowledge about historic culture, folk custom and production and life style of the Yi nationality to the next generation by singing narrative songs. As an important way of spreading Yi culture, folk songs of the Yi nationality in Liangshan have recorded the cultural inheritance of the Yi nationality

Folk songs of the Yi nationality have been advancing with the times. Some with obsolete contents have been eliminated one by one and a lot of melodies related to the life of modern people of the $\mathrm{Yi}$ nationality have been created. Many new contents have been created. Such music pieces not only maintain the original style and features of folk songs of the Yi nationality, but also richen era characteristics of folk songs with more abundant and vivid contents of melody. 


\subsection{Facilitate the improvement of cognition level of people for aesthetic and artistic value of folk songs}

Folk songs of the Yi nationality in Liangshan are treasures in Chinese national music as well as an important intangible cultural heritage in China. However, domestic and foreign popular music is constantly impacting Chinese traditional folk songs. Many young people have no interest in national music. Importance is not attached to aesthetic and artistic value of folk songs. Music personality and aesthetic nature of folk songs of the Yi nationality in Liangshan give people a strong sense of familiarity. People feel the charm and artistic value of national music culture again based on their own aesthetic height and aesthetic experience. Innovative development of folk songs of the Yi nationality in Liangshan makes us see the great vitality implied by folk songs and can improve our understanding of folk songs at deeper levels, our recognition for Chinese national music culture and our confidence in and sense of pride for music culture.

\subsection{Promote diversified development of music culture}

Popular music is developing rapidly at present. The younger generation pays attention to and is fond of music culture with commercial nature. Commercial speculation and operation seriously hinder the development of extensive and profound Chinese national music culture with a long history. As one of the original national music in China, folk songs of the Yi nationality in Liangshan fully show the charm of Chinese music culture and are the crystal of wisdom of laboring people of the Yi nationality as well as the manifestation of mental outlook and life customs of people of the Yi nationality. They have natural and simple melodies and important cultural value and have made important contributions to the diversified development of Chinese national music culture.

\section{Social functions of folk songs of Yi nationality in Liangshan}

Liangshan, Sichuan is the largest agglomeration area of the Yi nationality in China, which has a long history and rich cultural treasures. People of the Yi nationality have created and inherited many excellent folk songs of the Yi nationality in their labor, production and life over thousands of years. These folk songs run through all aspects of the life of people. Traditional folk songs of the Yi nationality are artistic epitome of the society of the Yi nationality as well as artistic reproduction of the emotion of people of the Yi nationality and their yearning for good life. They have unique social functions.

\subsection{Practical functions}

Folk songs of the $\mathrm{Yi}$ nationality in Liangshan have wide singing skills and patterns of manifestation. They are important treasures in Yi culture and true representation of social production and life, historic culture and development track of the Yi nationality in different historical periods as well as personal characteristics, thoughts and feelings of people of the Yi nationality. They have strong practical functions.

One of practical functions of traditional folk songs of the Yi nationality in Liangshan is the manifestation of laboring life. Most folk songs of the Yi nationality in Liangshan were improvised by laboring people in their production and life and created and sung by laboring people of the Yi nationality to overcome the severe natural environment and improve the joy of life and labor in their labor and production. They are an indispensable pattern of manifestation of music culture of the Yi nationality. Traditional folk songs of the Yi nationality are involved in diversified production and life of people. They manifest not only the laboring content of people of the Yi nationality, but also free and extended style and characteristics of folk songs of the Yi nationality. Traditional folk songs of the Yi nationality show artistic expression of the emotion of laboring people of the Yi nationality and their yearning for good life in production and life. The social system of the Yi nationality in Liangshan was slavery with strict hierarchy and sharp class conflicts before the foundation of New China. Folk songs created by people of the Yi nationality living under such background truly manifest their dissatisfaction about the current social situation, yearning for freedom and sigh for their fate. 


\subsection{Education function}

Artistic education fund is manifested in the impartment of cultural knowledge through artistic aesthetics and the influence on ideology and morality of people. Many theories of literature and art in ancient China fully recognized the education function of art, such as the theory of "propriety and music" of Confucius and "music shows the will" of Xuncius. Art can not only help people impart production and life knowledge and understand production and life through artistic work, but also educate people in the cultivation of noble moral sentiments and ideological quality. Liangshan, Sichuan had underdeveloped cultural information and few opportunities for communicating with the outside world and receiving formal education before emancipation. Folk songs became an important tool and main measure for the impartment of production and life knowledge and ideological and moral education. Folk songs of the Yi nationality in Liangshan involve all aspects of the social life of the Yi nationality in Liangshan, which are encyclopaedia reflecting historical culture, local conditions and customs and productive labor of the Yi nationality. Folk songs of the Yi nationality that could reflect the law of natural life and social reality could impart knowledge very well under the condition that most people were illiterate. They are an important tool for educating people of the $\mathrm{Yi}$ nationality. Folk songs of the Yi nationality in Liangshan reflect the social structure, folk customs, production and life style, ideological concepts and artistic aesthetics of people of the Yi nationality in different historical periods. These songs are main means for people of the Yi nationality to inherit historical culture, express thoughts and feelings, impart knowledge and cultivate thoughts.

\subsection{Entertainment function}

Excellent artistic work can provide people with a sense of joy and satisfaction. With constant progress of the society, material and cultural level of people has been improved and people have wider and more urgent pursuits for spiritual satisfaction. People of the Yi nationality create a lot of joyful folk songs. Folk songs of the Yi nationality in Liangshan originate from the production and life of laboring people and reflect true emotions of people at that time. Therefore, they have the function of delighting both mind and body and keeping up the spirit of people. People of the Yi nationality in Liangshan have created a lot of pleasant folk songs with the joy of life and folk characteristics in their production and life and artistic creation. These folk songs can be sung under happy atmosphere such as wedding and visitor welcoming. With humorous melodies, they combine education with recreation. People can feel ethics and morals and ideological concepts of the Yi nationality while laughing.

Entertainment function of folk songs of the Yi nationality can be divided into physical and spiritual entertainment. Physical entertainment function can be divided into group entertainment function and communication function. Folk songs of the Yi nationality are an artistic form reflecting the life and aspiration of people of the Yi nationality as well as an indispensable way of entertainment in the daily laboring life of people of the Yi nationality. Under the influence of the long-term primitive social system and production and living habits over thousands of years, people of the Yi nationality in Liangshan like group activities a lot. Many traditional customs continuing with living habits over thousands of years are accompanied by many relevant folk songs. Those folk songs are humorous and rich in philosophy and can heighten the atmosphere and educate the public. Drinking song in interactive group entertainment is an indispensable content on the wedding of people of the Yi nationality as well as a vital way of their entertainment and leisure. In slavery society, people of the Yi nationality in Liangshan did not have freedom and personal right. They could only realize self-entertainment and self-consolation with singing under oppression so that they would not lose confidence in life in the dark and miserable society.

Traditional folk songs can truly reflect the inner aspiration and wish of laboring people. They are not only an important way for laboring people to express their feelings, but also a tool for their communication.

Liangshan in Sichuan has poor transportation, backward science and technology and low social productivity. People of the Yi nationality living there can only plant according to the change law of nature. Therefore, they believe nature worship and revere spirits and ancestors. Such thought influences various aspects of the Yi society. Contents of many folk songs of the Yi nationality involve 
blessing and exorcism for treatment. Such folk songs have vivid and pleasant melodies and humorous lyrics which can inspire people.

\section{Importance and necessity of protecting and inheriting folk songs of the Yi nationality in Liangshan}

Folk songs exist in different historical periods of the Yi nationality. It can be said that folk songs have become the main carrier of the spiritual life of people of the Yi nationality. Folk songs of the Yi nationality exist where people of the Yi nationality live. This is effective inheritance of social and historic cultural development of the Yi nationality. They have important value of protection. Therefore, the government should promote healthy development of folk songs of the Yi nationality positively and protect and inherit folk songs of the Yi nationality effectively.

As a treasure in Chinese intangible cultural heritage, intangible cultural heritage protection of folk songs of the Yi nationality in Liangshan is far from enough. First, cost input of protection of the intangible cultural heritage is extremely lacking. Second, workers related to protection of the cultural heritage have limited working conditions and many theoretical and practical studies have not achieved the expected effect. Third, some extremely valuable and unique folk arts, manual skills, songs and dances of the Yi nationality haven't been explored deeply and inherited effectively. Forth, many precious historical cultural data have been damaged and it is very difficult to restore such data. Fifth, more importance is attached to declaration in the process of protecting and inheriting the intangible cultural heritage of folk songs of the Yi nationality and a protection mechanism is not established after successful declaration.

The existence of such problems seriously influences the effect of protection of folk songs of the Yi nationality as intangible cultural heritage. It is very difficult to continue to conduct extended and continuous work on the protection and inheritance of folk songs of the Yi nationality in Liangshan. For the protection and inheritance of folk songs of the Yi nationality in Liangshan as intangible cultural heritage, there is still a long way to go.

\section{Specific measures for protection and inheritance of folk songs of the Yi nationality in Liangshan from the perspective of intangible cultural heritage protection}

\subsection{Strengthen publicity and education of folk songs of the Yi nationality in Liangshan}

The department for protection of intangible cultural heritage should attach importance to and constantly enhance the role of civil organizations in daily publicity and education work and especially attach importance to their important role in inheritance and protection of intangible cultural heritage. The government should handle the relationship among protection, inheritance and development of the Yi nationality in Liangshan correctly and establish a scientific development mode under the construction principle of people first. The government can publicize, protect, inherit and develop folk songs of the Yi nationality in Liangshan through museum of folk songs of the Yi nationality in Liangshan, ethnic tourism of the Yi nationality in Liangshan and folk tourism site for song and dance of the Yi nationality in Liangshan.

\subsection{Integrate folk songs of the Yi nationality in Liangshan into college music teaching}

The government can set up vocal music teaching and research office of folk songs of the Yi nationality in colleges through the educational platform of colleges and universities or integrate folk songs of the Yi nationality into college vocal music teaching, enrich vocal music knowledge of students by imparting singing techniques of folk songs of the Yi nationality to students and meanwhile improve their speciality in vocal music so that they can develop folk songs of the $\mathrm{Yi}$ nationality better with their own vocal music knowledge. Such practice can not only achieve good effect of inheritance and development, but also promote the development of excellent Chinese national music culture and achieve the purpose of effective protection and inheritance of intangible cultural heritage. 


\subsection{Establish and implement a complete framework for protection work carefully}

The government should play a dominant role in the protection of cultural heritage. Relevant research scholars, experts, tourism enterprises, cultural industry and people at all levels of the society should participate jointly. The government should provide participants with a platform for making comments and suggestions and establish scientific protective measures through organization and summary of such comments and suggestions so as to promote greater effect of intangible cultural heritage protection.

\section{Conclusion}

As one of the carriers of Yi culture, folk songs of the Yi nationality in Liangshan record the production and life and cultural customs of laboring people of the Yi nationality. They are a treasure of minority songs as well as one of the typical patterns of intangible cultural heritage. Folk songs of the Yi nationality in Liangshan have not only promoted the development of Yi culture, but also made great contributions to the development of Chinese national music culture. The exploration on folk songs of the Yi nationality in Liangshan from the perspective of intangible cultural heritage has important realistic significance for improving the exertion of artistic value and social functions of folk songs of the Yi nationality in Liangshan and the understanding of people about the Yi nationality in Liangshan.

\section{Acknowledgement}

This research was financially supported by Talent plan of China West Normal University Study on Artistic Characteristics and Culture of Folk Songs of the Yi Nationality in Liangshan (No. 17YC550); Innovation team of China West Normal University Study on Folk Musical Culture in Bashu and Database Construction (No.CXTD2016-8).

\section{References}

[1] Wang Rui. Pattern of Manifestation and Mode Characteristics of Folk Songs of the Yi Nationality in Liangshan, Journal of Qujing Normal University, 2013, 02.

[2] Zhang Li, Sun Guoying. Music Form of Folk Songs of Yi Nationality in Liangshan, Sichuan, Chinese Music, 2013, 04.

[3] Wang Wenzhang. Study on Intangible Cultural Heritage Protection, Beijing: Culture and Art Press, 2013.

[4] Feng Jian. Brief Discussions on Aesthetic Taste of Folk Songs of Yi Nationality in Liangshan and Their Singing, National Music, 2013, 03.

[5] Han Jing. Study on Artistic Style and Singing Skills of Folk Songs of Yi Nationality, Shaanxi Normal University, 2011. 